\title{
然 \\ CÂMARA MIRIM DE BELO HORIZONTE: \\ ESTUDANTES EGRESSOS E SUAS PERCEPÇÕES SOBRE A EXPERIÊNCIA \\ EM UM PROJETO DE FORMAÇÃO POLÍTICA E CIDADÃ (2008-2015)
}

\section{CAMARA MIRIM OF BELO HORIZONTE: EGRESS STUDENTS AND THEIR PERCEPTIONS ON AN EXPERIENCE IN A POLICY \\ AND CITIZENSHIP TRAINING PROJECT (2008-2015)}

\author{
Alessandra Soares Santos ${ }^{1}$ \\ Araci Rodrigues Coelho ${ }^{2}$ \\ Santer Alvares de Matos $^{3}$
}

\begin{abstract}
Resumo: O Câmara Mirim é um projeto de educação para a cidadania por meio da formação política e do debate sobre temas de diversas ordens, coordenado pela Escola do Legislativo da Câmara Municipal de Belo Horizonte. O presente trabalho buscou compreender os impactos que o Câmara Mirim teve sobre a percepção da vida política dos vereadores mirins egressos, que são adolescentes de 12 a 15 anos de idade, estudantes dos últimos anos do Ensino Fundamental. Um questionário estruturado foi elaborado, constituindo-se como o principal instrumento metodológico. Os vereadores mirins egressos foram convidados a participarem da pesquisa e, após a análise dos dados, constatou-se que o Câmara Mirim é um projeto de educação para a cidadania com resultados efetivos e relevantes para aqueles que diretamente dele participaram. Ao final desse trabalho são apresentadas as considerações finais e os desdobramentos da pesquisa.
\end{abstract}

Palavras-chave: Câmara Mirim; Formação política e cidadã; Educação para a cidadania.

\begin{abstract}
The Camara Mirim is a citizenship education project through political formation and debate at about themes of various orders, coordinated by the Legislative School of the City Hall of Belo Horizonte. The present work sought to understand the impacts that the Camara Mirim had on the perception of the political life of the junior councilors. A structured questionnaire was developed, constituting itself as the main methodological instrument. The former junior councilors were invited to participate in the survey and, after analyzing the data, we verified that the Camara Mirim is a citizenship education project with effective
\end{abstract}

\footnotetext{
${ }^{1}$ Mestre e doutora em História pela UFMG, Co-coordenadora do Laboratório de Estudos e Pesquisas em Ensino de História e professora de História do Centro Pedagógico da UFMG (alessandrassantos@ hotmail.com).

${ }^{2}$ Mestre e doutora em Educação pela UFMG, pós-doutoranda em Ensino de História pela UEMG e professora de História do Centro Pedagógico da UFMG (aracoelho@gmail.com).

${ }^{3}$ Mestre em Ensino de Ciências e Matemática pela PUCMINAS, doutor em Educação pela UFMG e professor de Ciências do Centro Pedagógico da UFMG (santermatos@gmail.com).
} 
and relevant results for those who directly participated in it. At the end of this work the considerations and unfolding of this research are presented.

Keywords: Camara Mirim; Policy and citizenship training; Education for Citizenship.

\section{Câmara Mirim de Belo Horizonte}

O Projeto Câmara Mirim foi criado em 2008 pela Câmara Municipal de Belo Horizonte $(\mathrm{CMBH})$, por meio da Escola do Legislativo e em parceria com a Secretaria Municipal de Educação de Belo Horizonte e o Tribunal Regional Eleitoral de Minas Gerais. O projeto é um exemplo de programa de educação cívica que tem sido procurado por outras casas legislativas municipais interessadas no desenvolvimento de ações educativas desse tipo ou no aperfeiçoamento de suas câmaras mirins existentes. O objetivo central da proposta é este:

[...] promover a educação para a cidadania por meio da formação política e do debate sobre temas de ordem social, ambiental, econômica e política dos alunos [...], tendo como foco a instituição legislativa e utilizando, como instrumento pedagógico, a formação de um parlamento mirim do Município (BELO HORIZONTE, 2016).

Nessa perspectiva, o projeto almeja estimular a participação de estudantes dos últimos anos do Ensino Fundamental em questões de interesse da comunidade, além da busca pelo desenvolvimento da consciência política e da confiança nas instituições democráticas, qualificando os futuros eleitores e cidadãos.

Atualmente, com mandato de um ano, são eleitos por voto direto 45 vereadores mirins entre os alunos do terceiro ciclo do Ensino Fundamental de dez escolas municipais de Belo Horizonte selecionadas entre as diferentes regionais de ensino e do Centro Pedagógico da UFMG. Ao longo de oito anos de existência (2008-2015), foram eleitos 332 vereadores mirins de 56 escolas distintas. O projeto alcançou também milhares de estudantes que participaram como eleitores, debateram temas importantes para a sociedade e discutiram propostas para encaminhamento pelos vereadores mirins de sua escola.

O processo eleitoral nas escolas inicia-se com a inscrição, o cadastramento e a parametrização dos candidatos a vereadores mirins e eleitores. Depois, o processo segue com campanhas e debates perante a comunidade escolar, palestras de juízes do Tribunal Regional Eleitoral de Minas Gerais, visita a Câmara Municipal de Belo Horizonte, entre outras atividades. As eleições são realizadas em urnas eletrônicas do Tribunal Regional Eleitoral de Minas Gerais, nas escolas participantes do projeto naquele ano.

A posse dos vereadores mirins eleitos ocorre em sessão solene com a presença do Diretor da Escola do Legislativo da Câmara Municipal de Belo Horizonte, do Diretor do Centro Pedagógico da UFMG, da Secretária Municipal de Educação de Belo Horizonte, do Vereador 
Presidente da Câmara Municipal de Belo Horizonte e de um Juiz do Tribunal Regional Eleitoral de Minas Gerais.

Por meio de encontros mensais sediados na Câmara Municipal e do incentivo à realização de atividades extras realizadas nas escolas envolvendo a comunidade escolar, pretende-se atingir o objetivo central, qual seja, formar cidadãos conscientes e politicamente ativos. Com vistas a alcançar esse objetivo, os vereadores-mirins vivenciam dinâmicas como: discussões sobre a constituição dos três poderes (Executivo, Legislativo e Judiciário), principalmente, das funções e dos processos do Poder Legislativo Municipal; exercício de habilidades de oratória em debates de problemas presentes no município e nas comunidades; simulações de audiências públicas e reuniões plenárias; constituição, por voto, dos membros da Mesa Diretora e comissões temáticas; solenidade de descerramento da fotografia do vereador mirim eleito presidente em local nobre da Câmara Municipal de Belo Horizonte, entre outras atividades.

Importante destacar que, durante a legislatura, os vereadores mirins elaboram propostas, que são discutidas e votadas em turno único na plenária final. As propostas aprovadas são encaminhadas à Comissão de Participação Popular da Câmara Municipal de Belo Horizonte e, após análise de viabilidade, podem vir a ser acolhidas e apresentadas na forma de indicações ou projetos de lei, em nome da comissão, para tramitação formal, e assim possivelmente se tornarem leis.

Ao término da legislatura, há outra sessão solene com a presença de todos os parceiros, vereadores mirins e familiares, na qual os participantes relatam como foi atuar no projeto. Em seguida são anunciadas as escolas municipais que participarão do projeto no ano seguinte, tendo como critérios a permanência das escolas que se destacaram e a inserção de escolas de outras regionais do município de Belo Horizonte.

Ao final de cada encontro, vereadores mirins e escolas são convidados a realizarem uma avaliação do projeto. Essas avaliações são, geralmente, positivas, tanto por parte dos alunos quanto por parte dos professores que acompanham o projeto. Os alunos destacam o crescimento pessoal que o projeto thes proporcionou, e alguns deles acreditam que levarão tais conhecimentos e habilidades para toda a vida. Já a percepção dos professores reforça a opinião dos vereadores mirins destacando mudanças na vida escolar e crescimento no aspecto de socialização. No entanto, essas são avaliações feitas ao final da participação no projeto e no calor do último encontro do grupo e, por mais sinceras que sejam, não são suficientes para dimensionar os significados atribuídos à experiência dos vereadores mirins no projeto.

Nesse sentido, visando compreender um pouco mais sobre o papel que o projeto CAMIR pode representar na vida dos participantes, propôs-se a realização de uma pesquisa com os vereadores mirins egressos do projeto. Nesta pesquisa, buscou-se focalizar as representações construídas pelos vereadores mirins egressos sobre sua participação na Câmara Mirim e compreender os significados atribuídos ao impacto que essa experiência teve sobre a sua 
percepção da vida política. Conforme será visto adiante, estudos apontam que os programas de educação cívica e letramento político exercem um efeito significativo em seus participantes, pois ampliam seu conhecimento sobre o funcionamento das instituições democráticas e incentivam práticas que as valorizam e repercutem na sociedade. Nosso objetivo, portanto, foi avaliar a maneira como os estudantes percebem esse efeito.

\section{Educação para a cidadania}

As concepções de uma educação para a cidadania no Brasil são fruto de um contexto de mudanças políticas e sociais que vivenciamos desde o final dos anos 1970 e que foram aprofundadas com o movimento de redemocratização política no país nos anos 1980. Com a Constituição de 1988, estabelecemos a participação da sociedade na condução das políticas públicas e alçamos a cidadania como fundamento do Estado Democrático de Direito. Essa nova configuração teve impacto imediato no campo da educação, pois a formação para a cidadania se transformou em um requisito básico para a plena realização dos ideais de participação política lançados pela Constituição. De acordo com Sobral (2000), nesse novo contexto,

[...] a educação traria para o indivíduo a sua cidadania no sentido tanto do acesso ao ensino público e gratuito como da sua participação nas diferentes esferas do poder, o que significaria, para a sociedade, uma maior democratização e também uma maior autonomia [...] (SOBRAL, 2000).

Essa nova conjuntura abriu espaço para críticas de toda ordem ao modelo educacional então vigente e para o reconhecimento de sua incompatibilidade com a almejada consolidação da democracia, fundamentada na conquista de direitos civis, políticos e sociais do cidadão. Diante dessas críticas, muitas propostas de reformulação da educação, advindas de vários setores da sociedade - universidades, Estado, sindicatos, imprensa, igreja, associações de professores, entre outros - foram apresentadas e sistematicamente discutidas, dando origem a uma série de iniciativas. Entre elas, destaca-se a inserção de seções para os relatos de experiência de professores em publicações acadêmicas, revelando uma preocupação crescente com a prática docente voltada para a educação cívica. Esse movimento foi acompanhado pelo reconhecimento e pela participação dos governos dos estados nesse processo de reformulação do ensino e respaldado ou impulsionado, no nível federal, pela aprovação da nova Lei de Diretrizes e Bases (LDB), em 1996, e pelos Parâmetros Curriculares Nacionais, em 1997 (BRASIL, 1997).

De fato, a educação para o pleno exercício da cidadania está prevista nesses documentos, que indicam a necessidade da criação de situações de ensino e aprendizagem que favoreçam a compreensão do ambiente social do aluno, incluindo o conhecimento do sistema político e dos valores que fundamentam a vida em sociedade. O objetivo de tais orientações é favorecer a compreensão da cidadania “como participação social e política, assim como exercício de direitos 
e deveres políticos, civil e social, adotando, no dia a dia, atitudes de solidariedade, cooperação e repúdio às injustiças" (BRASIL, 1997).

A Constituição de 1988 atribuiu à educação formal, com a colaboração da sociedade, a responsabilidade de preparar a pessoa para o exercício da cidadania. Assim, o "educar para a cidadania" passou a ser um objetivo não só das escolas, mas também de outras instituições e associações. Na esteira da valorização dos preceitos da cidadania, surgiram outras iniciativas de conscientização política, como os programas de educação cívica - "programas promovidos com a finalidade de formação de cidadãos informados, politicamente ativos e com atitudes e valores em consonância com o regime democrático" (FUKS, 2014) - desenvolvidos pelas casas legislativas. O Projeto Câmara Mirim de Belo Horizonte surge nesse contexto.

Os estudos sobre a chamada "educação cívica" tiveram destaque a partir dos anos 1990, nos Estados Unidos, quando Niemi e Junn (1998) se apoiaram em um levantamento nacional de estudantes do Ensino Médio norte-americano para afirmar que as ações voltadas para a educação cívica podem ter impacto significativo sobre o conhecimento do funcionamento das instituições democráticas e sobre as atitudes dos estudantes no espaço público (NIEMI; JUNN, 1998). Desde então, outros estudos trilharam caminhos semelhantes ao concluírem que práticas educativas desse tipo podem tornar os alunos mais moderados e críticos diante de posições políticas radicais e mais propensos ao debate de ideias (SLOMCZYNSKI; SHABAD, 1988). Esses estudos acabaram questionando as posições de Langton e Jennings, segundo as quais ações educacionais promovidas com o intuito de ampliar a participação e a consciência política de crianças e adolescentes tinham resultado bastante limitado sobre a prática política imediata das comunidades, sendo necessária uma mudança geracional para que começassem a ser percebidas (LANGTON; JENNINGS, 1968).

Além da educação cívica, o letramento político é outro marco teórico na educação para cidadania. Segundo Crick (1998) apud Meneguin (2017):

[...] letramento político é a aprendizagem sobre como as pessoas podem se fazer atuantes na vida pública, por meio de conhecimento, habilidades e valores. Para ele, a vida pública aborda conhecimentos realistas, preparação para a resolução de conflitos e tomada de decisões, relativos aos problemas sociais e econômicos atuais, incluindo as expectativas individuais de cada um, a preparação para o mercado de trabalho, a discussão sobre a alocação de recursos públicos e a racionalidade dos impostos, entre outros. (CRICK, 1998 apud MENEGUIN, 2017, p.101)

Dessa forma, no letramento político, a interpretação do mundo por si só não é suficiente. O estudante deve compreender que pode mudá-lo na prática, isto é, o exercício da prática é um forte aliado na compreensão da política em sentido mais amplo (FOX, 2012). De igual forma, a educação cívica apresenta a necessidade de se ancorarem questões de fundo a ações práticas do fazer política (FUKS, 2014). 
As pesquisas mais recentes, portanto, sugerem que transformações de curto e médio prazo podem ser identificadas na cultura política de comunidades sujeitas às ações voltadas para a educação cívica. Finkel e Smith (2011) esclarecem que

Os teóricos inicialmente postularam que a aquisição de normas de regime democrático, valores e orientações participativas entre os indivíduos em democracias novas seria um processo de longo prazo ligado à modernização social e à substituição geracional. Uma série de pesquisas mais recentes sobre as novas democracias, no entanto, estabeleceu um novo truísmo: que as orientações democráticas são maleáveis, em médio e mesmo em curto prazo (FINKEL; SMITH, 2011, p. 417).

De acordo com Fuks (2014), hoje em dia, os estudos sobre o comportamento político têm como grande desafio explicar as mudanças relacionadas às atitudes, às tomadas de decisão e à participação política dos cidadãos. Questões que buscam compreender "o processo mediante o qual o cidadão apático se torna participativo" e as circunstâncias em que "atitudes políticas socialmente enraizadas perdem intensidade e, eventualmente, mudam de direção" ganharam destaque nos estudos mais recentes sobre socialização política (FUKS, 2014). Dessa forma, os programas educacionais voltados para a educação cidadã, como o Parlamento Jovem, analisado pelo referido autor, ou o Câmara Mirim, focalizado nesta pesquisa, transformaram-se em objetos privilegiados para trilhar algumas possibilidades de caminhos para essas mudanças. Acredita-se que "[...] os processos socializadores que ocorrem após a infância e em espaços mais amplos do que aqueles da socialização primária são relevantes para a formação e a transformação do perfil político dos indivíduos, em especial em ambientes com alto fluxo informacional" (FUKS, 2014).

Esses programas de educação cívica são iniciativas do Poder Legislativo que, para além do objetivo de consolidar práticas democráticas, pretendem fortalecer a imagem do Legislativo perante a sociedade, por meio de ações educativas, em parceria com outras instituições. Após participarem de programas desse tipo, é esperado que “[...] os jovens apresentem maior conhecimento político e que esse conhecimento promova algum impacto nas mudanças de atitudes, especialmente na confiança institucional" (SAMPAIO; SIQUEIRA, 2013, p.381). Portanto, avaliar o grau de influência que projetos como o Câmara Mirim exercem sobre seus participantes pode ajudar na ampliação de iniciativas desse tipo ou na reformulação de suas propostas pedagógicas.

\section{Estudantes egressos do projeto Câmara Mirim de Belo Horizonte}

Para a produção dos dados necessários para conhecermos a experiência dos vereadores mirins egressos e sua relação com as práticas políticas, foi elaborado um questionário (Apêndice) como principal instrumento metodológico dessa pesquisa. Segundo Gil (1999, p. 128), o questionário pode ser definido como "[...] a técnica de investigação composta por um número mais ou menos elevado de questões apresentadas por escrito às pessoas, tendo por objetivo o 
conhecimento de opiniões, crenças, sentimentos, interesses, expectativas, situações vivenciadas etc."

Foi escolhido tal instrumento, concordando com o autor (GIL, 1999), pois ele apresenta, entre outras, as seguintes vantagens sobre as demais técnicas de produção de dados: a) possibilita atingir grande número de pessoas, mesmo que estejam dispersas numa área geográfica muito extensa; b) garante o anonimato das respostas; c) permite que as pessoas o respondam no momento em que julgarem mais conveniente; e d) não expõe os pesquisadores à influência das opiniões e do aspecto pessoal do entrevistado.

Partindo dos princípios elencando por Gil (1999), conseguiu-se atingir um número significativo de jovens dispersos pela cidade, por meio do envio do link do questionário por correio eletrônico, uma vez que ele foi disponibilizado no formato formulário do Google. $\mathrm{O}$ conjunto de questões submetidas aos estudantes egressos, de forma auto aplicada, teve o objetivo de coletar tantas informações sobre o seu perfil familiar, quanto sobre suas crenças, sentimentos e valores relacionados à cidadania e à vida política. Para tanto, foram elaboradas questões fechadas, abertas e dependentes sobre fatos (dados concretos como idade, por exemplo), crenças e atitudes (dados referentes a fenômenos subjetivos) e comportamentos (passado ou presente) (GIL, 1999).

Dessa forma, dos 120 vereadores mirins egressos que se conseguiu contatar ${ }^{4}$ e que aceitaram participar da pesquisa, 83 responderam ao questionário. Esses 83 respondentes representam $25 \%$ do universo total dos participantes do projeto entre o período de 2008-2015, ou seja, ao longo dos seus oito anos de existência. Representam também um universo representativo dos anos de realização da Câmara Mirim de Belo Horizonte desde 2008 (Gráfico 1). A maioria deles é do gênero feminino (51,8\%), tem entre 15 e 18 anos e frequentava o $9^{\circ}$ ano do Ensino Fundamental quando participaram do Câmara Mirim (44,6\%). Hoje, a maioria é estudante do Ensino Médio (39,8\%) ou Superior (22,9\%).

\footnotetext{
${ }^{4}$ Utilizamos o cadastro organizado pelo projeto para contactar os ex-vereadores mirins. No entanto, esse cadastro foi se aperfeiçoando ao longo dos anos. Assim, por exemplo, em 2008, não há registros individuais dos alunos, apenas dos representantes e das escolas. O registro individual, com telefones e endereços, só foi feito em 2009. A partir de 2010 foram registrados também os emails de cada ex-vereador mirim. Durante três meses tentamos contato com todos eles, inicialmente por telefone, em seguida por email. Muitos desses endereços estavam desatualizados. Assim, muitas ligações não completavam ou não atendiam e muitos emails voltaram. Por fim, buscamos contactar os participantes do projeto ainda pelas redes sociais. Foi dessa forma que chegamos ao total de 120 ex-vereadores, ou seja, 36, $14 \%$ do universo total da pesquisa. Esses, após receberem informações gerais sobre a pesquisa, foram convidados a participar dela. Todos responderam positivamente ao convite. No entanto, como já é esperado nesse tipo de pesquisa (GIL, 1999), $30 \%$ deles, apesar de aceitarem participar, acabaram não respondendo ao questionário.
} 


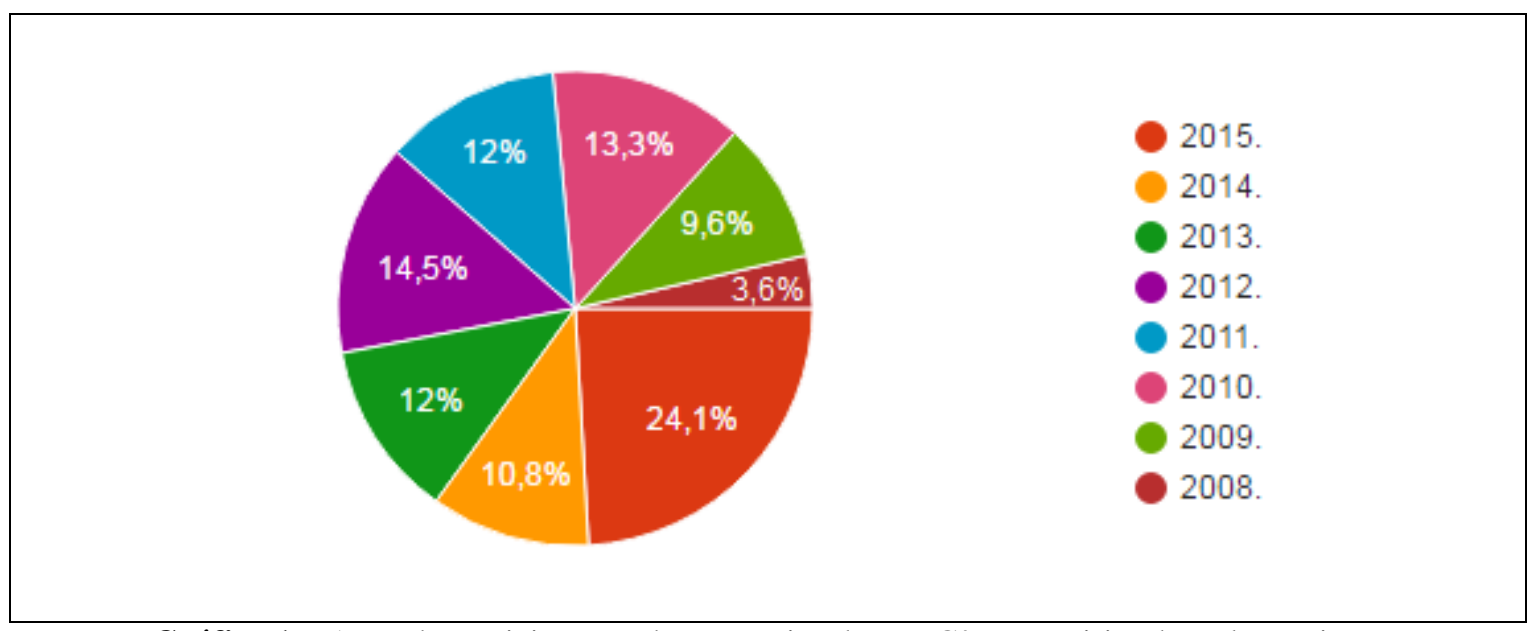

Gráfico 1 - Anos de participações dos entrevistados no Câmara Mirim de Belo Horizonte.

Fonte: Elaborado pelos autores

Em relação ao interesse pela política, $82 \%$ dos estudantes egressos do Câmara Mirim se auto classificaram como interessados ou muito interessados (Gráfico 2) e quase $87 \%$ afirmaram se informar sobre questões ligadas à política diariamente ou semanalmente (Gráfico 3), principalmente por meio da mídia digital (jornais, revistas e blogs), conforme Gráfico 4.

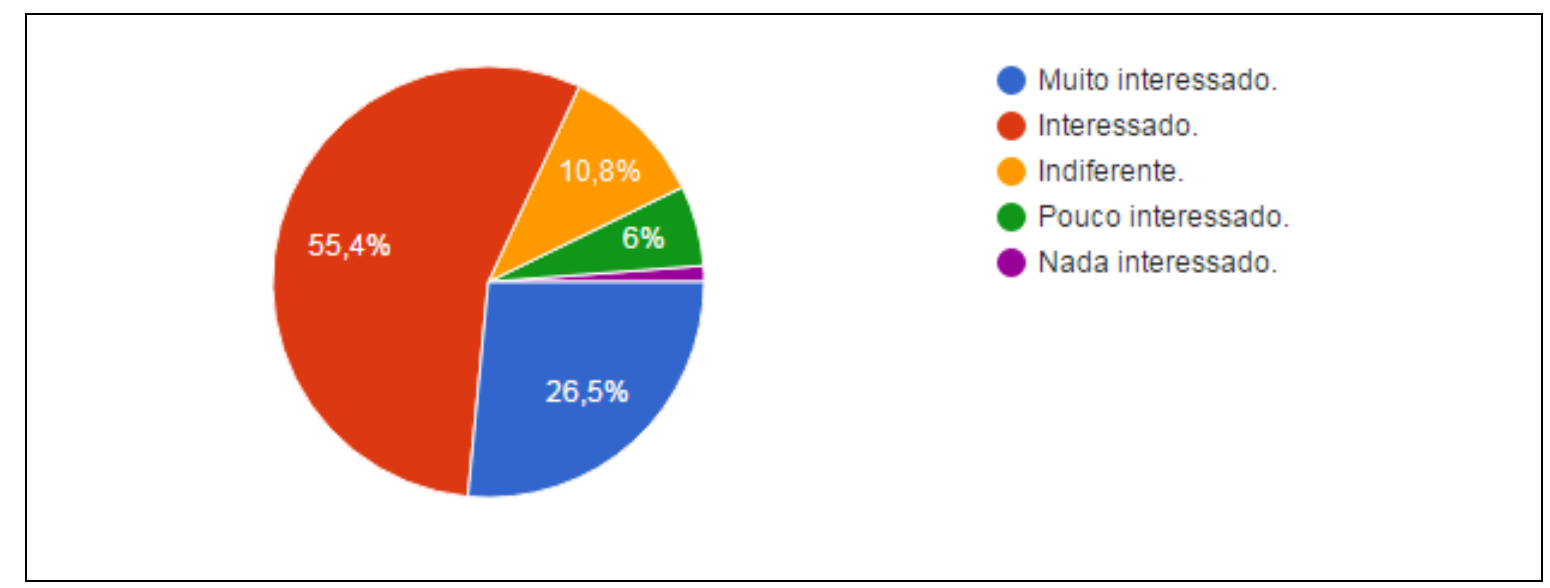

Gráfico 2 - Classificação quanto ao interesse pela política.

Fonte: Elaborado pelos autores

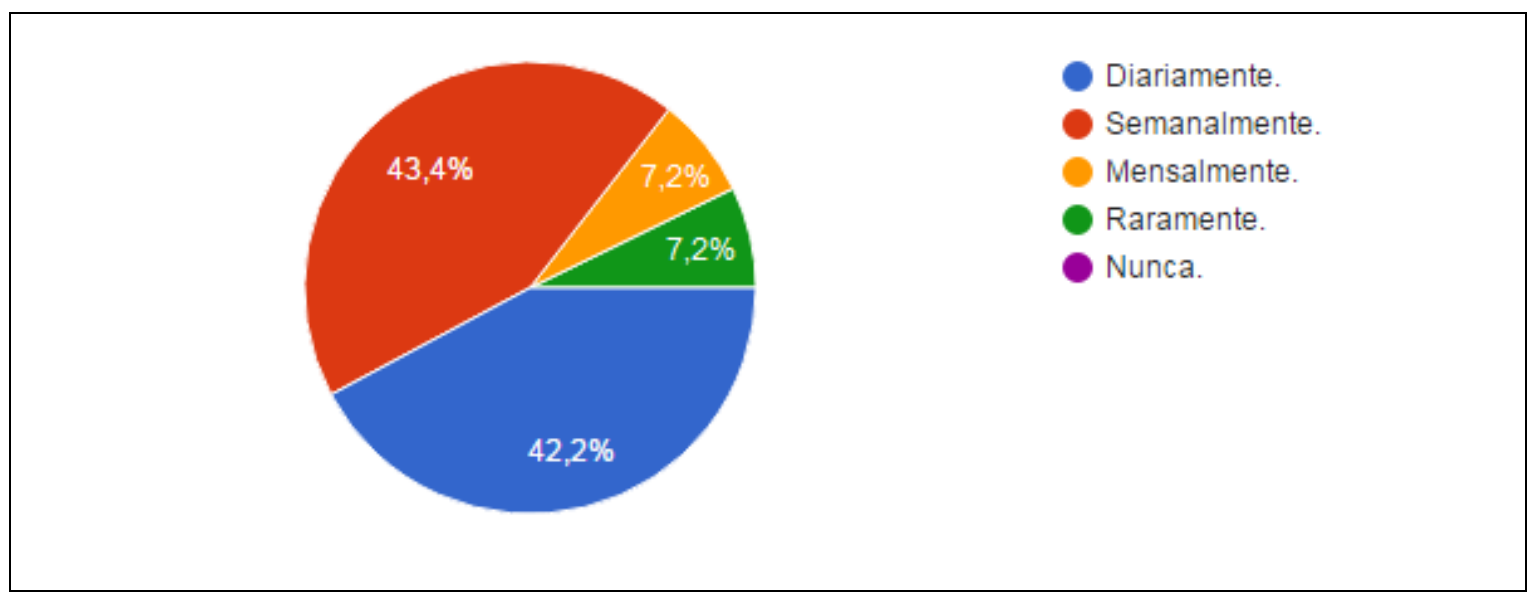

Gráfico 3 - Frequência com que se informa sobre questões relacionadas à política.

Fonte: Elaborado pelos autores 


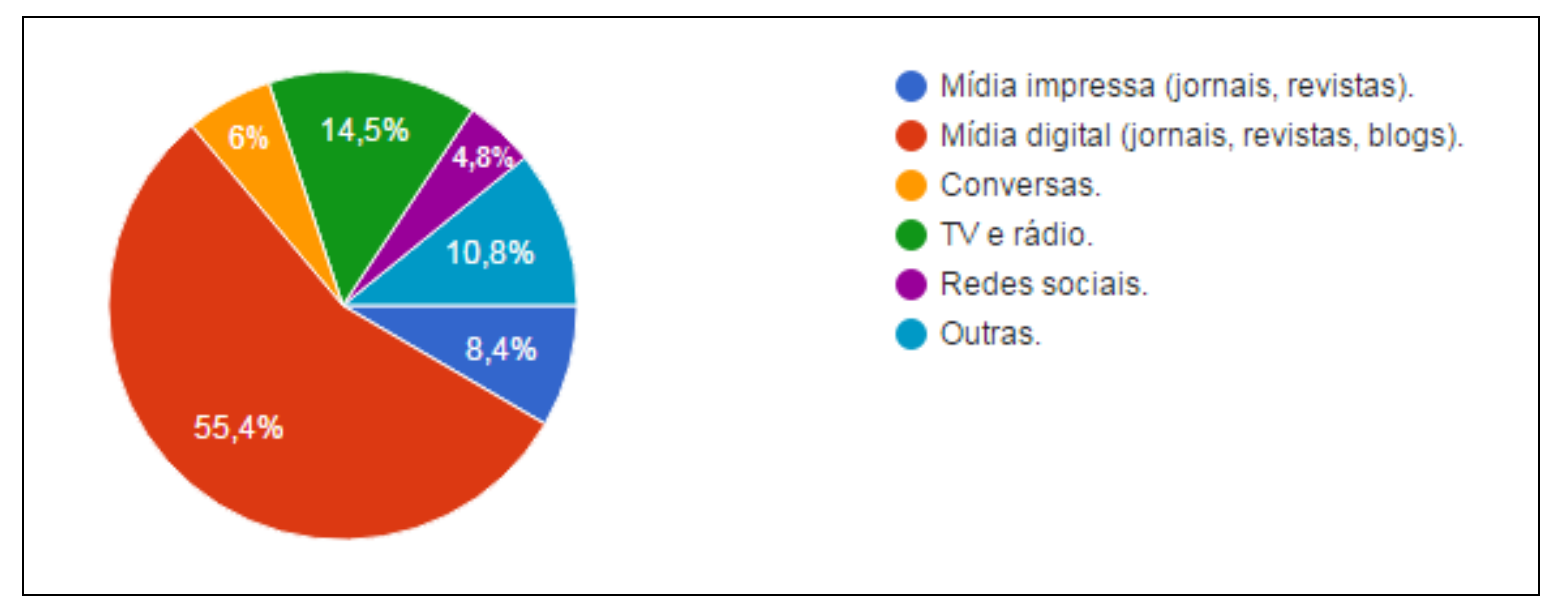

Gráfico 4 - Obtenção de informações sobre questões ligadas à política.

Fonte: Elaborado pelos autores

Embora a maioria informe que nunca participou de nenhum outro projeto voltado para a formação política ou exerceu algum tipo de representação política (Gráfico 5), aqueles que declararam já terem participado de outros projetos de formação política existentes em Belo Horizonte citaram o Parlamento Jovem, mini ONU e Ouvidoria Jovem. Dos 13\% que assumiram outras representações políticas antes da experiência no Câmara Mirim, 23\% se envolveram com o Grêmio Estudantil e outros $23 \%$ foram representantes de turma. Estes dados são bastante significativos, principalmente se considerarmos que nem todas as escolas possuem agremiações estudantis. Outros $23 \%$ participaram de órgãos colegiados de suas instituições de ensino. Assim, no universo de $13 \%$ que já tinham assumido cargos de representação, $69 \%$ se envolveram em atividades políticas relacionadas à sua escola (grêmio estudantil, representação de turma, conselho escolar, caixa escolar etc.).

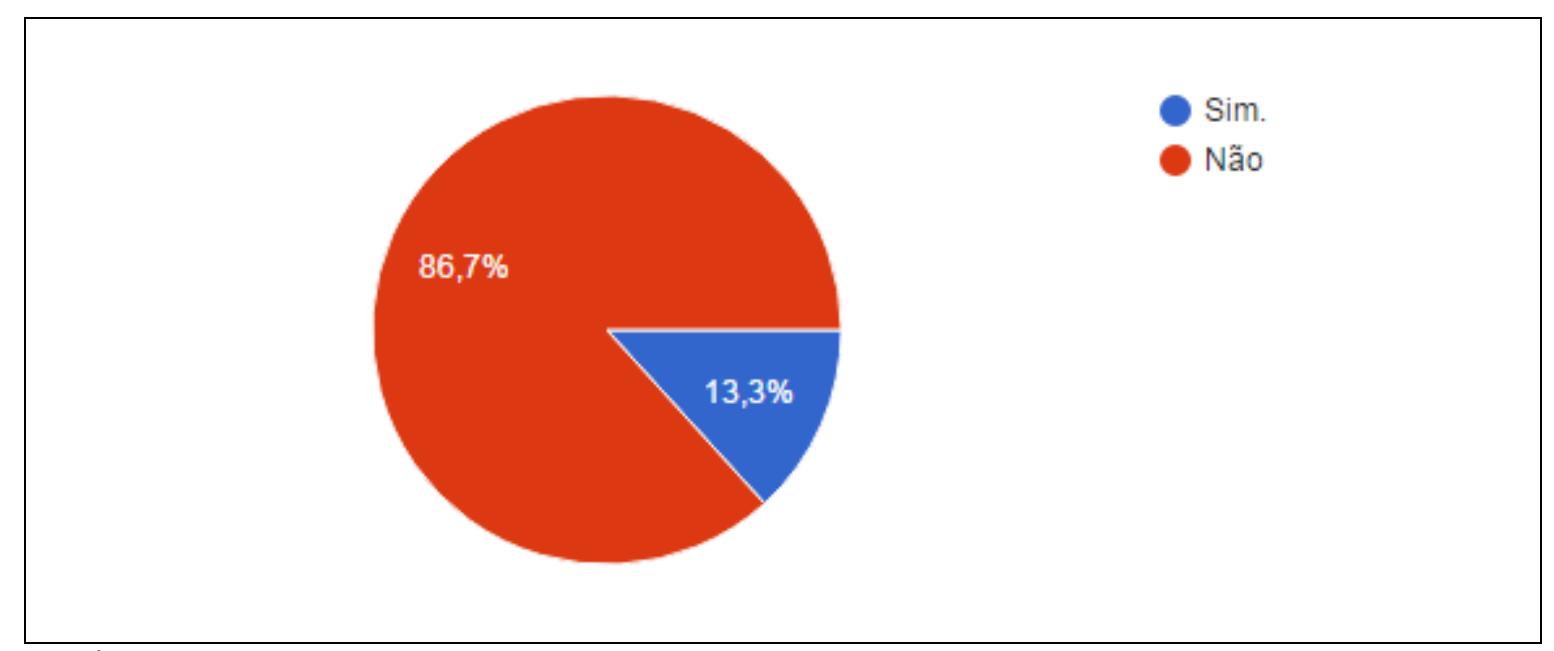

Gráfico 5 - Participação em outros projetos voltados para a formação política e/ou exercício de outras atividades de representação política.

Fonte: Elaborado pelos autores 
Dos 83 entrevistados, 97\% avaliaram positivamente sua atuação como vereador mirim, conforme Gráfico 6.

Já 83\% dos entrevistados afirmaram que sua participação no Câmara Mirim contribuiu para a sua formação política (Gráfico 7). Ao esclarecerem de que forma teria se dado essa contribuição, alguns egressos explicaram que tiveram mais conhecimento sobre o sistema político brasileiro e sobre o trabalho dos vereadores dentro da Câmara. Também informaram que compreenderam o funcionamento dos poderes Executivo, Legislativo e Judiciário, que aumentou seu interesse pela política e que ficaram mais críticos em relação a esse tema.

Um bom exemplo dessa contribuição do Câmara Mirim à formação política de seus egressos é a trajetória de uma estudante que participou do projeto em 2009, quando cursava o sexto ano do Ensino Fundamental. Sua mãe é dona de casa e seu pai, mecânico, e ambos não completaram o Ensino Fundamental, além de nenhum membro de sua família ter tido participação em associações ou alguma representação política. Entretanto, atualmente cursando o Ensino Superior, a estudante foi candidata à vereadora nas eleições municipais de 2016. Ela atribui à participação no Câmara Mirim o seu interesse em ser vereadora.

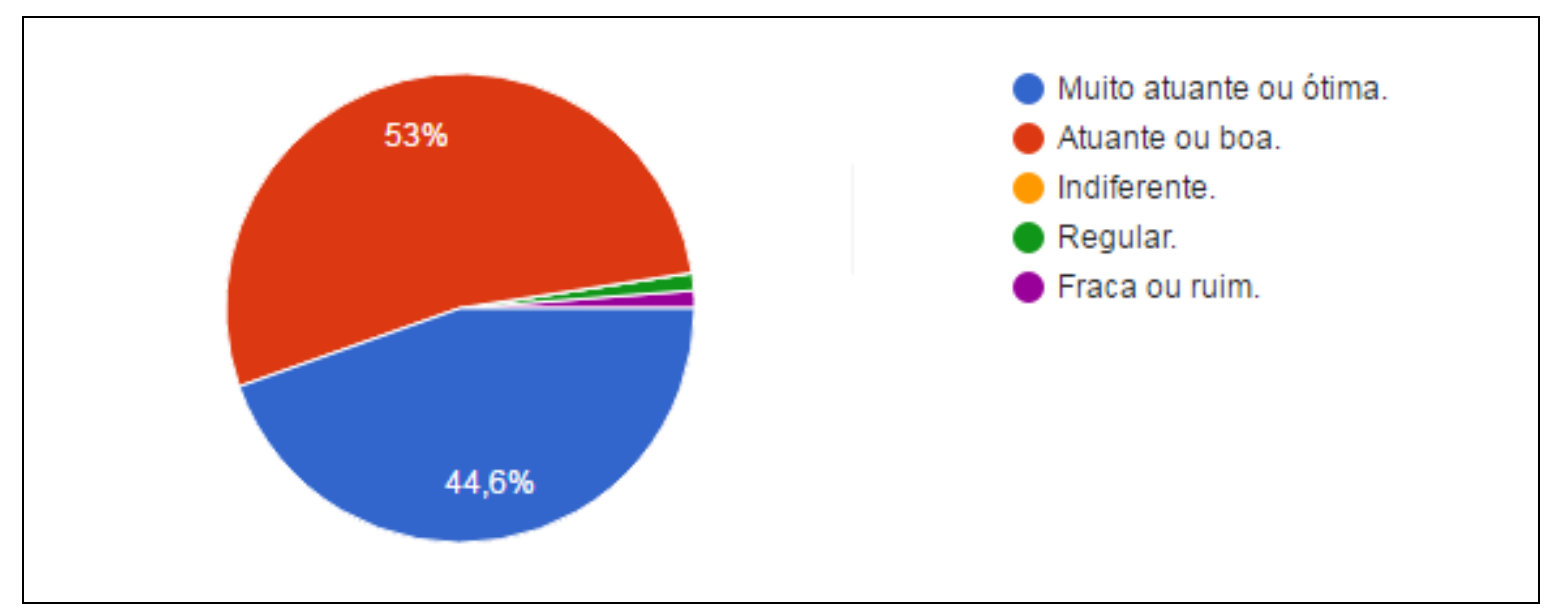

Gráfico 6 - Avaliação da participação como vereador mirim.

Fonte: Elaborado pelos autores

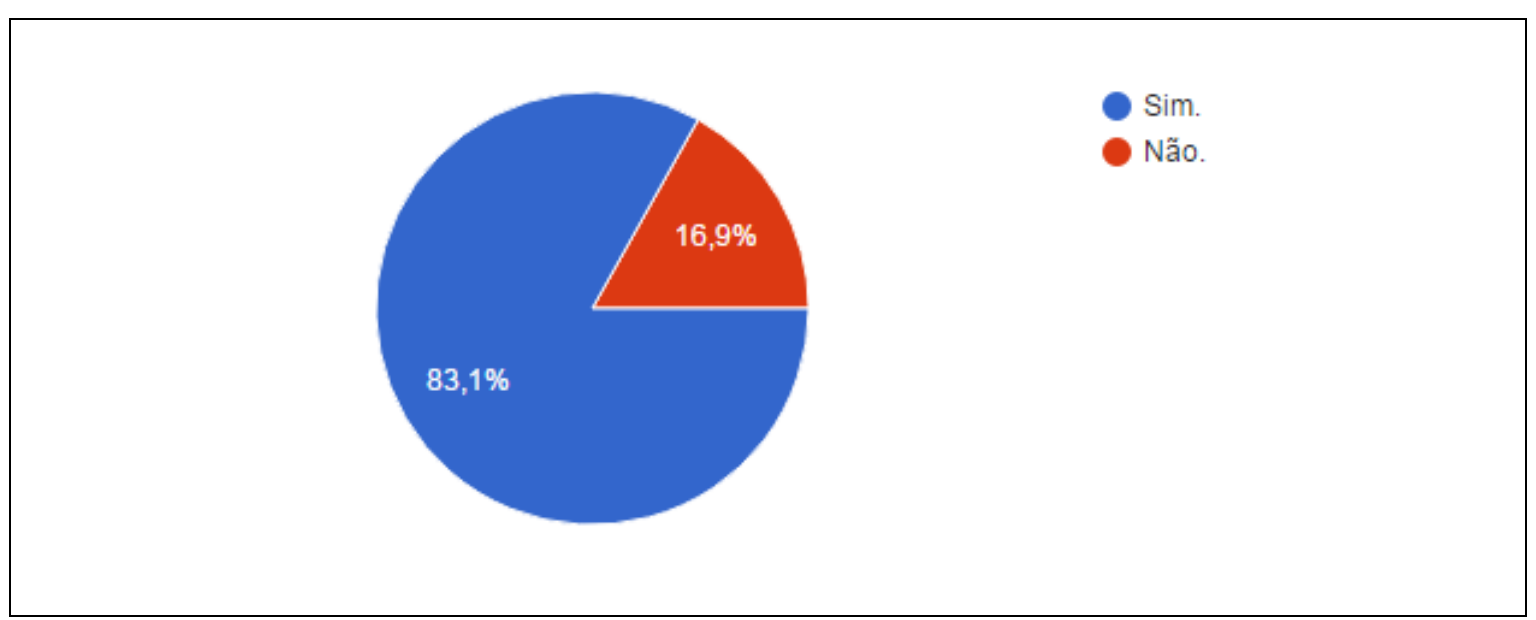

Gráfico 7 - Participação no Câmara Mirim e sua contribuição para a formação política.

Fonte: Elaborado pelos autores 
Alguns dos ex-vereadores mirins chamaram a atenção para o fato de que sua participação no projeto teria ajudado a transformar seu olhar para o mundo e para a sociedade, incentivando uma participação mais ativa nas questões de interesse coletivo. É o caso, por exemplo, de um estudante que atualmente cursa o Ensino Médio e trabalha como monitor de informática. Ele participou do Câmara Mirim em 2011, quando estava no sétimo ano do Ensino Fundamental. Seus pais não concluíram a Educação Básica, mas em seu círculo familiar havia uma pessoa ligada à associação de moradores de seu bairro, que o incentivou a participar efetivamente dela, com outras lideranças políticas. O interesse que ele desenvolveu pelas questões políticas o faz acompanhar diariamente o noticiário sobre o tema. Ele classifica sua participação no Câmara Mirim como muito atuante, e sua percepção sobre a formação adquirida no projeto pode ser citada literalmente: "[...] foi de grande valia para a minha pessoa, atuante na sociedade como cidadão. Engajado na política, fiquei consciente de como funcionava os três poderes constituintes de nossa nação. Fico feliz por não ser mais um analfabeto político". Além disso, ele declara que sua participação no Câmara Mirim mudou a sua vida, na medida em que alterou sua percepção do que é a política. Segundo ele, “[...] pensamentos contrários à política foram lançados por terra, uma vez que a política engloba todos os aspectos de nossas vidas, assim, não podemos ignorá-la ou deixar que outros decidam o que é dever nosso".

Além de reconhecerem a importância do projeto para a sua formação política, $81 \%$ dos entrevistados ainda afirmaram que a participação no Câmara Mirim acarretou alguma mudança em sua vida (Gráfico 8). Tal afirmação pode ser percebida a partir de outras declarações que ressaltaram as contribuições do projeto para a melhoria das interações sociais, para a exposição de ideias e opiniões de forma clara, para a superação da timidez, para a valorização da diversidade e para o respeito à alteridade.

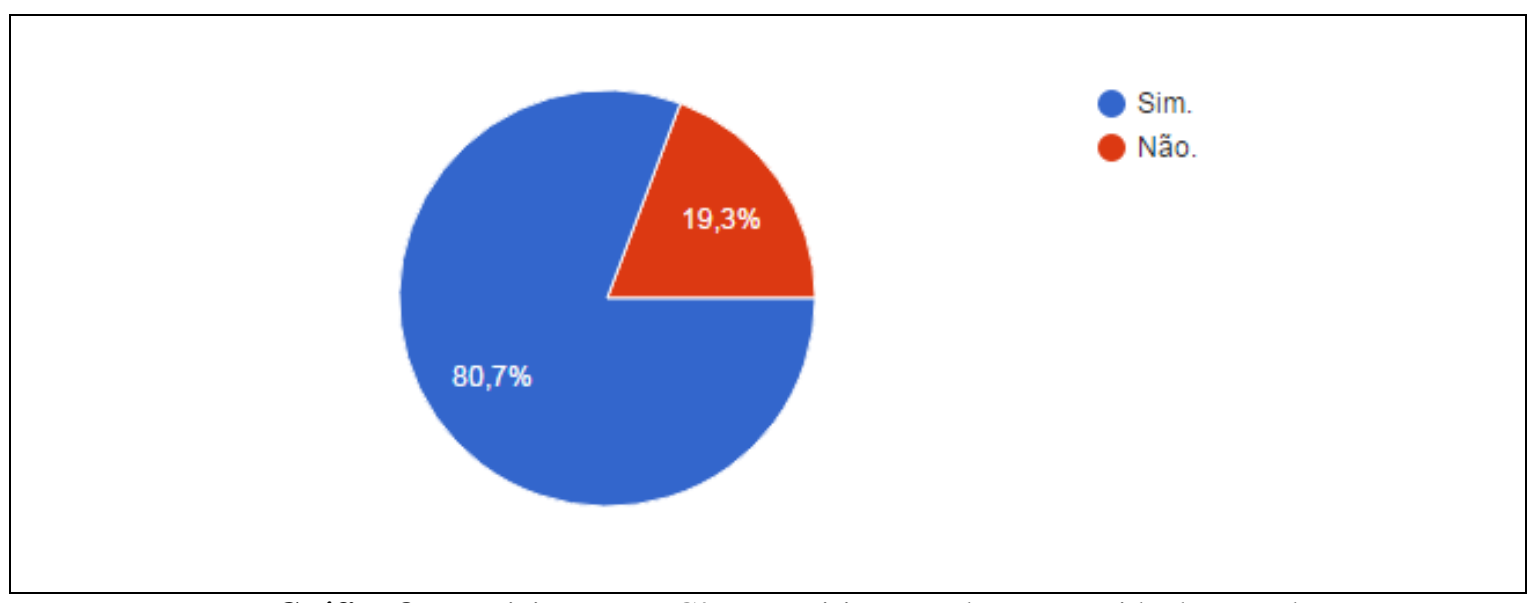

Gráfico 8 - Participação no Câmara Mirim e mudanças na vida dos estudantes. Fonte: Elaborado pelos autores 
Como exemplo, podemos citar a declaração de uma estudante que participou do Câmara Mirim em 2015, quando cursava o nono ano do Ensino Fundamental. Segundo ela,

Hoje tenho mais respeito com os outros independentes de quem seja e valorizo a diversidade. Tenho mais sabedoria e paciência para enfrentar certos problemas, tanto na escola, em casa ou onde eu estiver. Aprendi como ser uma boa cidadã e hoje sei que tenho direitos. Aprendi como e quando usar meus direitos e ter igualdade perante a lei. Tenho mais argumentos para me expressar [...]. Tenho mais confiança em minhas capacidades e percepção de minhas limitações e aumentou meus interesses na política e tudo que a envolve. Estas foram as mudanças que me ocorreram depois de minha participação no Câmara Mirim.

Entre aqueles que já haviam participado de outro projeto de educação para a cidadania, a avaliação de que a participação no Câmara Mirim provocou alguma mudança em sua vida foi de $100 \%$. Quando se observa o grupo que nunca havia participado de nenhum outro projeto, o percentual fica próximo da população geral, caindo para quase $78 \%$ os que sentiram mudanças em suas vidas. A partir desse cruzamento de dados, podemos afirmar que aquelas pessoas que já participaram de outros projetos semelhantes avaliam de forma mais positiva a potencialidade do projeto para provocar mudanças em suas vidas.

Após literatura e dos indícios apresentados pelos gráficos até o momento, pode-se inferir que o Câmara Mirim despertou o vereador mirim egresso para o universo da política. A sustentação para tal inferência se baseia na relação entre o declarado interesse e engajamento dos vereadores mirins egressos por questões de ordem política. Além disso, baseia-se em outras pesquisas segundo as quais o estudante que passa a se interessar e se informar mais sobre política teria maior propensão a se engajar em atividades cívicas e de letramento político no futuro (ZUKIN et al., 2006; LUSKIN et al. 2007; FUKS; PEREIRA, 2011). Dessa forma, conclui-se que os vereadores mirins egressos teriam maior propensão a se engajarem em atividades de ordem política como declarado por eles nas respostas da presente pesquisa.

Também mapeamos o perfil familiar dos entrevistados. O grau de escolaridade majoritário de pais/mães dos egressos do Projeto Câmara Mirim é o Ensino Médio completo $(32,5 \%)$. Apenas cerca de 10\% dos pais/mães dos respondentes têm Ensino Superior completo ou incompleto. Dentre as profissões majoritárias, $10,2 \%$ estão relacionadas à prestação de serviços domésticos (faxineira, empregada doméstica e cuidador de idosos) e 8,4\% são autônomos (Quadro 1).

Perguntamos, ainda, se algum membro da família participa ou já participou de alguma associação e/ou representação política, e 20,5\% responderam afirmativamente (Gráfico 9). Nas famílias em que alguém já participou de alguma associação política ou assumiu alguma representação política - como participação em sindicato, filiação a partido político, participação em associação de bairro, etc. -, o percentual dos vereadores mirins que também assumiram outras funções de representação antes do Projeto Câmara Mirim - como representante de turma, 
participação em grêmio estudantil e conselho escolar, etc. - é maior. Esse dado sugere que os vereadores mirins com esse histórico familiar de representação são mais propensos a também se engajar em atividades políticas.

Quadro 1 - Profissões majoritárias de pais/mães.

\begin{tabular}{|c|c|}
\hline PROFISSÃO & $\%$ \\
\hline Desempregado & 2,4 \\
\hline Setor de beleza & 3,0 \\
\hline Não sabe & 3,6 \\
\hline Professor & 4,2 \\
\hline Construção civil & 5,4 \\
\hline Técnicos & 5,4 \\
\hline Aposentados & 6,0 \\
\hline Motoristas & 6,0 \\
\hline Comércio & 6,6 \\
\hline Dona de casa & 7,2 \\
\hline Autônomos & 8,4 \\
\hline Serviços domésticos & 10,2 \\
\hline Outros & 32,0 \\
\hline
\end{tabular}

Fonte: Elaborado pelos autores

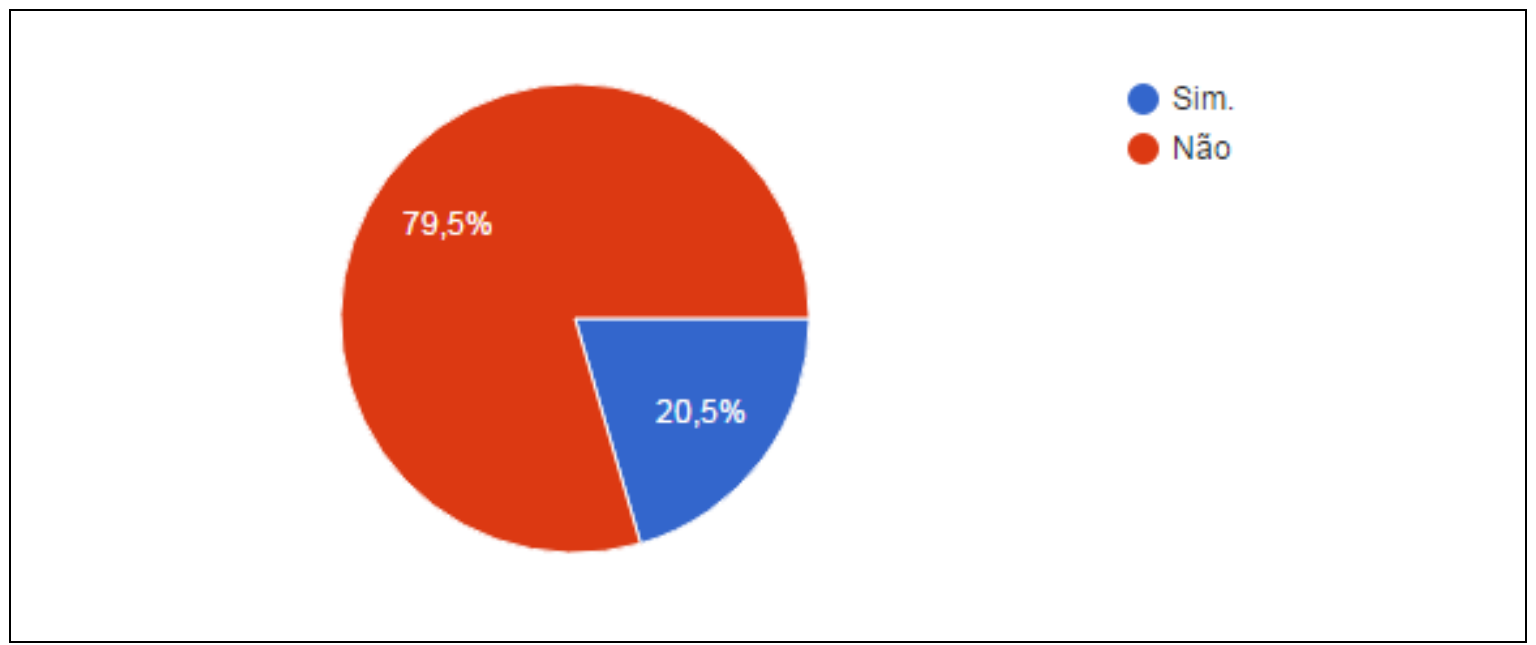

Gráfico 9 - Membro da família participa/participou de associação e/ou representação política.

Fonte: Elaborado pelos autores

Como exemplo, podemos citar o caso de um estudante que atualmente cursa o Ensino Médio e trabalha como estoquista. Ele participou do Câmara Mirim em 2014, quando cursava o nono ano do Ensino Fundamental e já tinha participado como membro efetivo do colegiado e do grêmio estudantil de sua escola. Sua mãe possui o Ensino Médio completo e seu pai não concluiu o Ensino Fundamental. Outros familiares participaram de atividades ligadas à representação política. Ele declarou o seguinte: 
Meu tio foi presidente da associação de moradores do meu bairro e meu bisavô foi articulador da associação de moradores e mobilizou até os bairros vizinhos para a construção da escola do bairro e para o asfaltamento das ruas. Inclusive, minha família teve a honra de ter o nome dele em uma rua.

Muito interessado em política, ele declarou que acompanha as notícias sobre o tema diariamente. Na sua avaliação, o Projeto Câmara Mirim de Belo Horizonte contribuiu para a sua formação ética e cidadã. Além disso, ele afirma que aprendeu vários métodos para recorrer às autoridades e que os debates e conversas com os colegas foram muito produtivos para o seu crescimento pessoal.

De fato, entre os vereadores mirins cujos familiares tiveram algum tipo de participação política, foi menor o percentual daqueles que avaliaram o projeto como menos transformador em sua vida. Considerando o total de entrevistados, $19 \%$ afirmaram que não sentiram mudanças em suas vidas após a participação no Câmara Mirim. Observou-se que, entre os ex-vereadores mirins cujos pais tinham participação política, é menor o percentual daqueles que acham que o projeto não resultou em mudanças em sua vida, apenas $11,7 \%$.

Outro aspecto importante evidenciado pela pesquisa é a relação entre o grau de instrução dos familiares e o interesse dos estudantes por política. Quando analisamos as mães e os pais que têm uma escolaridade superior ao Ensino Médio completo, $90 \%$ de seus dependentes se declararam interessados ou muito interessados em política. Na direção contrária, entre as mães e pais que têm grau de instrução inferior ao Ensino Médio incompleto, o percentual de filhos e filhas interessados ou muito interessados em política cai para 77\%. Portanto, parece haver uma relação muito evidente entre instrução e interesse por política e cidadania, indicando que uma mudança mais radical na formação para a cidadania nas escolas deve ser acompanhada por de uma ampliação do acesso dos cidadãos ao ensino superior.

Entre aqueles que consideraram sua participação como vereadores mirins como boa ou ótima, 94,5\% afirmaram acompanhar diariamente assuntos relacionados à política, sobretudo por meio das mídias digitais. Além disso, $89 \%$ dos participantes desse grupo disseram ser muito interessados ou interessados em política. Acreditamos que o interesse pela política de parte desse grupo de estudantes analisados pode estar relacionado ao interesse dos familiares sobre o tema, pois $21 \%$ deles tiveram pais em cargos de representação política.

Quando analisamos apenas os participantes que afirmaram ser interessados ou muito interessados em política, percebemos que em $22 \%$ dos casos eles tiveram alguém na família que se engajou em alguma atividade política, em âmbito classista, comunitário, municipal e até nacional. E apenas $8,8 \%$ daqueles que se disseram muito interessados ou interessados em política afirmaram que a experiência no Projeto Câmara Mirim não foi relevante para sua trajetória.

Concluímos, portanto, em consonância com outros trabalhos que buscaram analisar o perfil político de jovens com participação em iniciativas ou programas de socialização política, que o ambiente familiar e o ambiente escolar podem exercer significativa influência sobre o 
conhecimento, as atitudes, os valores e a participação política dos estudantes egressos da Câmara Mirim (FUKS, 2014; SILVA, 2012; VERBA; SCHLOZMAN; BRADY, 1995). Assim, concordamos com Fucks (2014) e outros autores segundo os quais a atuação familiar em atividades sociais e políticas parece ser de fato bastante relevante para a formação dos alunos, influindo no maior aproveitamento desses ao participarem dos projetos de educação para a cidadania, como o Câmara Mirim.

No início da pesquisa com os egressos do Câmara Mirim, supusemos que, como atividade de caráter voluntário e extracurricular, ela poderia atrair apenas estudantes que já tinham algum interesse prévio por política. Contudo, a pesquisa nos mostrou que cerca de $15 \%$ dos estudantes que participaram do projeto e responderam ao questionário declararam ser pouco interessados, nada interessados ou indiferentes à política. Mesmo assim, metade desses estudantes desinteressados em política têm consciência de que o tema tem muita influência sobre sua vida. Surpreendentemente, apesar de não terem interesse prévio pelo assunto, 100\% desses estudantes afirmaram terem sido atuantes ou muito atuantes como vereadores mirins. Além disso, $58 \%$ deles admitiram que o projeto contribuiu bastante para a sua vida.

Um bom exemplo foi de uma estudante que participou do projeto em 2012. Na pesquisa ela se declarou indiferente em relação à política; no entanto, ela afirmou que os principais canais de informação sobre o assunto são as mídias digitais, que ela diz acompanhar semanalmente, e a escola. A estudante declarou ainda que, durante o projeto, ela foi uma vereadora mirim atuante e que, por causa desse engajamento, sua vida mudou conforme declaração a seguir: "me fez ter maior conhecimento da área política atualmente, pois o interesse que tive pela política foi após a experiência no Câmara Mirim".

Portanto, se por um lado o interesse dos estudantes pela temática da política e da cidadania contribuiu para que eles se engajassem no projeto, por outro lado, para aqueles que não se interessavam pelo assunto, a participação no Câmara Mirim significou um instrumento de mudança em sua postura diante do tema. Isso ficou evidenciado por seu envolvimento extremamente positivo como vereador mirim.

\section{Considerações finais}

Após a análise dos dados aqui apresentados, esperamos ter demonstrado que o Projeto Câmara Mirim é um projeto de educação para a cidadania que de fato apresenta resultados efetivos e relevantes para os seus participantes diretos: os ex-vereadores mirins. Esses resultados podem ser traduzidos, por exemplo, pela mudança de postura diante da política e pela compreensão da importância da participação cidadã na coletividade. Eles se traduzem, também, pelo aumento do conhecimento sobre o sistema político brasileiro e sobre o trabalho dos vereadores dentro da Câmara e pela maior compreensão sobre o funcionamento dos Poderes Executivo, Legislativo e 
Judiciário. E, ainda, no dizer de alguns, esses resultados contribuíram para a transformação da forma de olhar o mundo e a sociedade, incentivando uma participação mais ativa nas questões de interesse coletivo.

O presente estudo realizou uma primeira análise dos dados produzidos pelos questionários. Outras análises e produções de mais dados deverão ser realizadas propiciando o adensamento reflexivo sobre a compreensão do Projeto Câmara Mirim em seus egressos. Portanto, observamos que o CAMIR se constitui, também, como espaço para ações de pesquisas no campo da educação para a cidadania e política.

\section{Referências}

BELO HORIZONTE. Câmara Municipal. Projeto Câmara Mirim (Camir). Belo Horizonte: Escola do Legislativo da Câmara Municipal, 2016.

BRASIL. Ministério da Educação. Parâmetros Curriculares Nacionais: introdução aos parâmetros curriculares nacionais. Brasília: MEC/SEF, 1997.

FINKEL, S. E.; SMITH, A. E. Civic education, political discussion, and the social transmission of democratic knowledge and values in a new democracy: Kenya 2002. American Journal of Political Science, v.55, n.2, p.417-435, 2011.

FOX, N. H. Teaching (is not) activism. Radical Teacher, n. 94, p. 14-23, 2012.

FUKS, M. Explicando os efeitos de programas de socialização política: a experiência do Parlamento Jovem no Brasil. Opinião Pública, Campinas, v. 20, n. 3, p. 425-449, 2014.

FUKS, M; PEREIRA, F. B. Informação e conceituação: um estudo sobre a dimensão cognitiva da desigualdade política entre jovens de Belo Horizonte. Revista Brasileira de Ciências Sociais, v. 26, n. 76, p. 123-143, 2011.

GIL, A. C. Métodos e técnicas de pesquisa social. São Paulo: Atlas, 1999.

LANGTON, K. P; JENNINGS, M. K. Political socialization and the high school civics curriculum in the United States. American Political Science Review, v.62, n.3, p.852-867, 1968.

LUSKIN, R. et al. Deliberation in the schools: a way of enhancing civic engagement?

Presented at the Biennial General Conference of the European Consortium for Political Research. 2007. Disponível em:

$<$ http://citeseerx.ist.psu.edu/viewdoc/download?doi=10.1.1.176.6381\&rep=rep1\&type=pdf $>$. Acesso em: 02 fev. 2018.

MENEGUIN, A. M. P. L. Plenarinho: novos paradigmas para novas gerações. E-Legis, Brasília, n.22, p.99-128, 2017.

NIEMI, R.; JUNN, J. Civic education: what makes students learn. New Haven: Yale University Press, 1998.

SAMPAIO, T.; SIQUEIRA, M. Impacto da educação cívica sobre o conhecimento político: a experiência do programa Parlamento Jovem de Minas Gerais. Opinião Pública, Campinas, v.19, n.2, p.380-402, 2013.

SILVA, R. G. da. Juventude e educação cidadã: estudo sobre os impactos do Parlamento Jovem de Minas Gerais. Teoria e Cultura, v.7, n.1-2, p.55-68, 2012.

SLOMCZYNSKI, K. M.; SHABAD, G. Can support for democracy and the market be learned in school? A natural experiment in post-communist Poland. Political Psychology, v.19, n. 4, p. 749$779,1988$. 
SOBRAL, F. A. da F. Educação para a competitividade ou para a cidadania social? São Paulo em Perspectiva, São Paulo, v.14, n.1, p.3-11, 2000.

VERBA, S.; SHLOZMAN, L.; BRADY, E. Voice and equality: civic voluntarism in American politics. Cambridge: Harvad University Press, 1995.

ZUKIN, C; et al. A new engagement? Political, civic life, and the changing American citizen. Oxford: Oxford University Press, 2006.

\section{APÊNDICE}

Questionário de produção de dados da pesquisa e disponibilizado no padrão Formulário Google.

Sobre você:

1. Nome:

2. Idade:

3. Gênero:

4. Profissão:

5. Escolaridade:

6. Além da Câmara Mirim, você já participou ou participa de algum outro projeto voltado para a formação política?

7. Antes da Câmara Mirim, você já assumiu ou assume algum tipo de representação política?

\section{Sobre sua família:}

8. Profissão da mãe:

9. Escolaridade da mãe:

10. Profissão do pai:

11. Escolaridade do pai:

12. Algum membro da sua família participa ou já participou de alguma associação política? Qual?

\section{Sobre a política:}

13. Em relação à política você é:

14. Como você se informa sobre questões ligadas à política?

15. Com que frequência você se informa sobre questões ligadas à política?

16. Você acha que o que acontece na política tem influência na sua vida? Como?

\section{Sobre sua participação na Câmara Mirim:}

17. Em que ano você participou da Câmara Mirim?

18. Qual ano escolar você frequentava quando participou como vereador mirim?

19. Em qual escola você estuda ou estudava quando participou da Câmara Mirim?

20. Como você avalia sua participação como vereador mirim?

21. Você considera que sua participação na Câmara Mirim contribuiu para a sua formação política? Justifique. 
Câmara Mirim de Belo Horizonte: estudantes egressos e suas percepções sobre a experiência em um projeto de formação política e cidadã (2008-2015)

22. Você considera que sua participação na Câmara Mirim provocou alguma mudança em sua vida? Justifique.

Artigo recebido em: 05/03/2017

Artigo aceito para publicação em: 17/05/2017 